\title{
Assessment of left ventricular regional function in affected and carrier dogs with duchenne muscular dystrophy using speckle tracking echocardiography
}

\author{
Hiroshi Takano' ${ }^{1}$ Yoko Fujii ${ }^{*}$, Naoko Yugeta ${ }^{1,2}$, Shinichi Takeda ${ }^{2}$ and Yoshito Wakao'
}

\begin{abstract}
Background: Two-dimensional speckle tracking echocardiography (STE) is a relatively new method to detect regional myocardial dysfunction. To assess left ventricular (LV) regional myocardial dysfunction using STE in Duchenne muscular dystrophy model dogs (CXMDJ) without overt clinical signs of heart failure.

Methods: Six affected dogs, 8 carrier dogs with $C X M D_{\jmath}$, and 8 control dogs were used. Conventional echocardiography, systolic and diastolic function by Doppler echocardiography, tissue Doppler imaging (TDI), and strain indices using STE, were assessed and compared among the 3 groups.

Results: Significant differences were seen in body weight, transmitral E wave and $\mathrm{E}^{\prime}$ wave derived from TDI among the 3 groups. Although no significant difference was observed in any global strain indices, in segmental analysis, the peak radial strain rate during early diastole in posterior segment at chordae the tendineae level showed significant differences among the 3 groups.

Conclusions: The myocardial strain rate by STE served to detect the impaired cardiac diastolic function in CXMD, without any obvious LV dilation or clinical signs. The radial strain rate may be a useful parameter to detect early myocardial impairment in CXMD.
\end{abstract}

\section{Background}

Duchenne progressive muscular dystrophy (DMD) is characterized by progressive degeneration of skeletal and cardiac muscles with fibrotic tissue replacement and fatty infiltration [1]. Resulting myocardial dysfunction has been estimated to be responsible for death in $20 \%$ of human DMD patients [2,3].

Echocardiography is one of the useful noninvasive methods used to assess cardiac function in patients and animals with Duchenne's cardiomyopathy [4-9]. It is possible that the recognition of earlier subclinical cardiac systolic or diastolic dysfunction could allow for an early medical approach, thus improving long-term cardiovascular outcomes. Several studies have demonstrated the usefulness of tissue Doppler imaging (TDI) to detect subclinical myocardial systolic and diastolic dysfunction in patients with normal conventional echocardiographic parameters [10].

\footnotetext{
* Correspondence: fujiiy@azabu-u.ac.jp

'Department of Surgery 1, School of Veterinary Medicine, Azabu University, Kanagawa, Japan

Full list of author information is available at the end of the article
}

These studies have also confirmed that myocardial velocities, myocardial wall-thickening velocities, myocardial velocity gradients and strain during systole and early diastole in the left ventricular free wall were reduced in patients [11-15] and dogs with DMD [16,17]. However, strain measurements derived from TDI involve several disadvantages including angle-dependence and the limitations of an available cardiac region for an assessment. Since it has been reported that the distribution of myocardial lesions detected by magnetic resonance imaging (MRI) and single photon emission computed tomography (SPECT) varied among DMD patients [18-20], TDI might underestimate the severity of myocardial dysfunction in certain patients.

Two-dimensional speckle tracking echocardiography (STE) is a new approach designed to assess left ventricular function in humans and animals [21,22]. STE has no angle-dependence and allows the assessment of any region of the heart. Usefulness of STE analysis in human patients with idiopathic dilated cardiomyopathy to detect systolic and diastolic dysfunction has been described in 
several reports. STE provides several advantages over TDI, in for example, estimation for the increase in LV filling pressure [23-25]. In addition, STE has the ability to detect regional myocardial dysfunction [22]. We hypothesized that STE could detect early myocardial lesions in patients with Duchenne's cardiomyopathy without clinical signs. To our knowledge, there have been no reports assessing the cardiac function of Duchenne's cardiomyopathy using STE.

Canine X-linked muscular dystrophy in Japan $\left(\mathrm{CXMD}_{\mathrm{J}}\right)$ is a Beagle-based dog colony established by artificially inseminating frozen semen from spontaneous Golden retriever muscular dystrophy. $\mathrm{CXMD}_{\mathrm{J}}$ has been reported to be comparable to human patients and dogs with DMD [9,26-28]. The purpose of the present study was to assess left ventricular regional myocardial dysfunction using STE in affected and carrier $\mathrm{CXMD}_{\mathrm{J}}$ dogs without overt clinical signs of heart failure.

\section{Methods}

\section{Animals}

Beagles aged 8 months old or more from a $\mathrm{CXMD}_{\text {J }}$ colony at the Division of Laboratory Animal Resources, National Institute of Neuroscience, National Center of Neurology and Psychiatry used in the present study included 6 dogs affected with $\mathrm{CXMD}_{\mathrm{J}}, 8$ carrier dogs, and 8 control dogs. Control dogs had no history of cardiopulmonary diseases, and each had a normal physical examination, standard 6 lead electrocardiogram and conventional echocardiogram. Dogs were categorized as affected, carrier or normal (control) dogs on the basis of DNA analysis conducted immediately after the birth [27]. All experiments were approved by the Ethics Committee for the Treatment of Laboratory Animals of the National Institute of Neuroscience (approval No. 20-03 and 21-03).

\section{Echocardiographic Examination}

All echocardiographic images were acquired using Vivid S6 (GE Medical System, Tokyo, Japan) ultrasound unit equipped with a $7 \mathrm{MHz}$ transducer and were obtained by one trained examiner (HT). Dogs were restrained manually in lateral recumbency. Skilled experimental animal technicians handled the dogs and assisted in the experiments. For dogs that became agitated, the examination was performed 15 minutes after sedation with acepromazine $(0.01 \mathrm{mg} / \mathrm{kg}$, IV, A.C.P. $10,10 \mathrm{mg} / \mathrm{mL}$, Delvet, The State of New South Wales, Australia) and buprenorphine $(0.0075 \mathrm{mg} / \mathrm{kg}$, IV, Lepetan injection, 0.2 $\mathrm{mg} / \mathrm{mL}$, Otsuka, Tokyo, Japan). ECG monitoring with clear $\mathrm{R}$ wave recognition was recorded in concurrence with an echocardiographic examination using the same ultrasound unit. The mean value of variables in 3 consecutive cardiac cycles was used for statistical analysis.

\section{Conventional Echocardiography}

M-mode echocardiographic measurements were made from the right parasternal short-axis view at the chordae tendineae $(\mathrm{Ct})$ level (LV end-diastolic and end-systolic internal diameters [LVIDd and LVIDs], and fractional shortening $[\mathrm{FS}]$ ). We calculated left ventricular end-diastolic volume (EDV), left ventricular end-systolic volume (ESV) and left ventricular ejection fraction (EF) from LV internal diameters using the Teichholz method. LV enddiastolic and end-systolic volume indices (EDVI and ESVI) were derived from EDV and ESV divided by body surface area (BSA), respectively [29]. Diameters of the left atrium (LAD) and aortic root (AoD) were measured from the right parasternal short-axis view at the heart base level by B-mode method, and the LA/Ao ratio was calculated [30].

\section{Systolic and Diastolic Function by Doppler Echocardiography and TDI}

Systolic time intervals (pre-ejection period [PEP] and LV ejection time $[\mathrm{ET}]$ ) were measured using an aortic flow velocity curve [31]. Transmitral inflows (TMF) were created from the left parasternal apical 4-chamber view. Early (E wave) and late (A wave) filling velocities, the $\mathrm{E}$ wave deceleration time (DcT) and E/A ratio were measured from the transmitral flow tracing. Left ventricular isovolumic relaxation time (IVRT) was calculated as the time difference between the intervals from the beginning of the Q wave on the ECG to the onset of early diastolic flow and intervals from the $\mathrm{Q}$ wave to the end of aortic flow tracing. Tissue Doppler trace of mitral annulus velocity (MAV) on the lateral side was obtained from the left parasternal apical 4-chamber view to measure peak velocities during systole (S') and during early diastole (E'). Then, the E/E' was calculated [32,33].

\section{Speckle Tracking Echocardiography (STE)}

Right parasternal short-axis views at $\mathrm{Ct}$ level were used to measure all STE indices below, because myocardial lesion of dogs with $\mathrm{CXMD}_{\mathrm{J}}$ was reported to be localized in free wall at basal level of LV [9]. Images were acquired in cine loops triggered by the QRS complex, saved in digital format, and analyzed using off-line software (EchoPAC PC '08 ${ }^{\mathrm{a}}$ ). The principal of speckle tracking analysis has been described in several previous studies [21,22,34-37]. All analysis was performed by one observer (HT).

For the each of 6 regions of interest, peak systolic radial and circumferential strains (SR and SC), and peak radial and circumferential strain rates during systole and early diastole $\left(\mathrm{SrR}_{\mathrm{S}}, \mathrm{SrR}_{\mathrm{E}}, \mathrm{SrC}_{\mathrm{S}}\right.$ and $\left.\mathrm{SrC}_{\mathrm{E}}\right)$ were measured at the level of the Ct (Figure 1). The E/SrR $R_{E}$ and $E / S r C_{E}$ were derived from $\mathrm{E}$ divided by $\mathrm{SrR}_{\mathrm{E}}$ and $\mathrm{SrC}_{\mathrm{E}}$, respectively. Since the values of radial and circumferential 


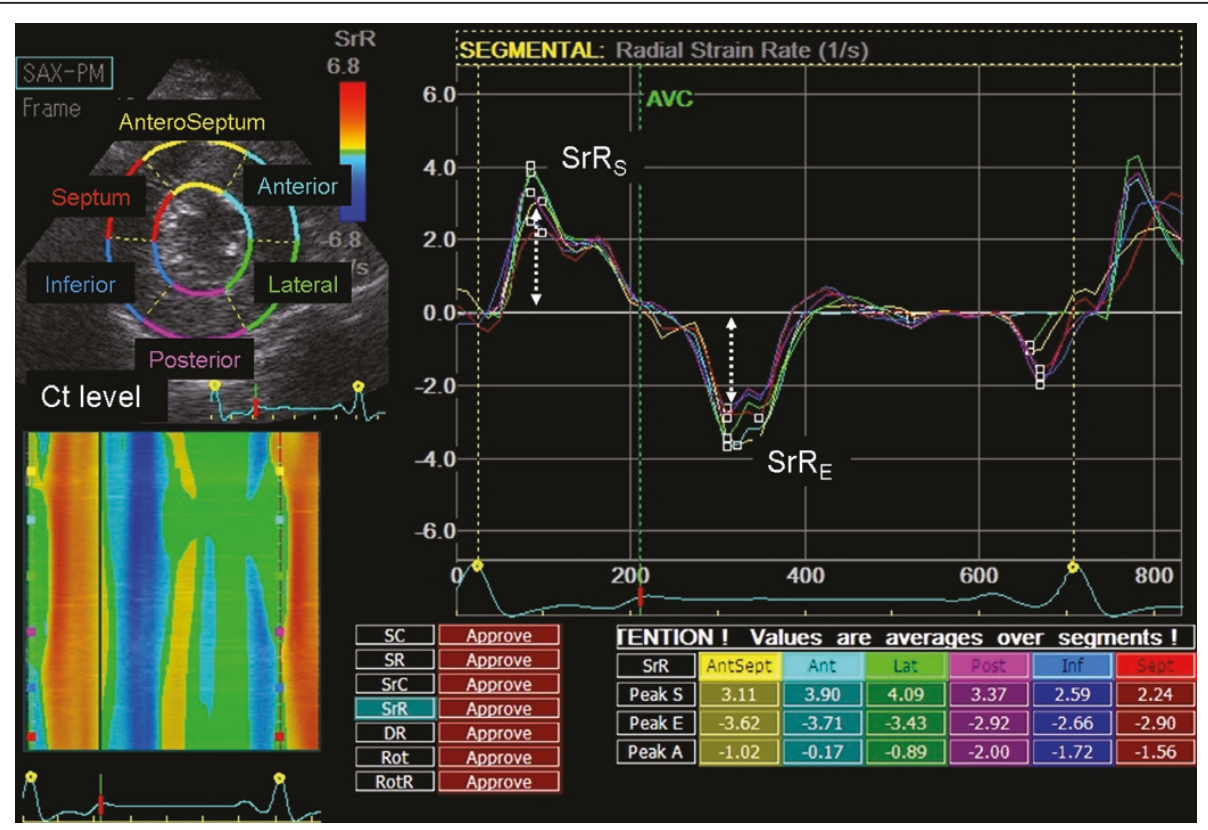

Figure 1 Radial strain rate tracking for one cardiac cycle obtained from the parasternal short-axis view at Ct level. Six curves with different colors depict respective each myocardial segments of left ventricule (anteroseptum, anterior, lateral, posterior, inferior and septum). Systolic and early diastolic values of radial strain rate $\left(S r R_{S}\right.$ and $\left.S r R_{E}\right)$ were calculated.

direction were calculated from 6 segments as described previously, the mean of all 6 segments and the mean of each segmental value were calculated for all parameters.

\section{Experimental Protocols}

Conventional echocardiographic parameters, systolic time intervals, diastolic functional parameters and STE indices were obtained and compared among the affected, carrier and normal dogs.

Since sedatives were administered when a dog was not cooperative, the influence of sedation on all indices was assessed using 6 normal dogs. Parameters were obtained at baseline and 15 minutes after sedation with acepromazine $(0.01 \mathrm{mg} / \mathrm{kg}, \mathrm{IV})$ and buprenorphine $(0.0075 \mathrm{mg} / \mathrm{kg}, \mathrm{IV})$, and then compared.

For the assessment of reproducibility, intraobsever variability of STE analysis was assessed by use of images from 6 normal dogs. Using same cine loops, each STE value was determined again 3 weeks after the primary analysis.

\section{Statistics}

Comparisons among the 3 groups were performed using one-way ANOVA. A post hoc testing for the difference among the groups was performed by the Steel method. The assessment of the influence of sedation was performed using the paired $t$-test. When the normality test failed, the Wilcoxon signed-rank test was applied. Intraobserver variability was express as mean of absolute difference as the percentage of the mean of two absolute measurements. A value of $P<0.05$ was considered statistically significant.

\section{Results}

\section{Animals}

The characteristics of affected, carrier and normal dogs in the present study are shown in Table 1 . There was a significant difference in BW among the 3 groups.

\section{Influence of Sedation}

A significant difference between pre- and post-sedation values was seen in HR and ESVI. In addition, a significant difference was also seen in the A wave of TMF (Table 2).

\section{Conventional Echocardiography}

No significant difference among the 3 groups was noted in any parameters (Table 3). Mild mitral regurgitation (MR) was detected using the color Doppler imaging in 1 carrier dog.

\section{Systolic and Diastolic Function by Doppler Echocardiography (Table 4)}

Significant differences were seen in E wave of TMF and MAV on the lateral side (E') among the 3 groups.

\section{Speckle Tracking Echocardiography}

The frame rate used for this study to analyze STE indices ranged from 72 to 93 frames per second. Frames 
Table 1 Characteristics of each group

\begin{tabular}{lcccc}
\hline Index & Unit & Normal dogs & Carrier dogs & Affected dogs \\
\hline Number & & 8 & 8 & 6 \\
Gender & F/M & $4 / 4$ & $8 / 0$ & $3 / 3$ \\
Number of sedated dogs & months & $32.86 \pm 29.73$ & 6 & 4 \\
Age & $\mathrm{kg}$ & $12.19 \pm 1.04$ & $33.13 \pm 23.68$ & $24.50 \pm 15.27$ \\
Body weight & lit.41 & & $9.49 \pm 2.05 \dagger$ \\
\hline
\end{tabular}

†: Significant difference compared with normal dogs by multiple comparison $(P<0.05)$.

per cardiac cycle were $57.38 \pm 6.53,49.36 \pm 10.70$ and $49.44 \pm 12.16$ frames, in normal, carrier and affected dogs, respectively, and there was no significant difference among the 3 groups $(P=0.21)$. Intraobserver variability of measurements was 3.6 to $13.2 \%$. Table 5 shows the results of global values in the STE indices of the 3 groups. In strain indices, only $\mathrm{E} / \mathrm{SrR}_{\mathrm{E}}$ had significant differences between normal and carrier dogs.

$\mathrm{SrR}_{E}$ in the posterior segments were significantly decreased in carrier and affected dogs when segmental values were compared with normal dogs (Figure 2 and table 6).

\section{Discussion}

In the present study, no significant difference was found in any parameters using conventional echocardiography among the 3 groups, which indicated no apparent LV dilation or systolic dysfunction with normal FS in affected and carrier dogs.

$\mathrm{SrR}_{\mathrm{E}}$ has been reported to show a significant correlation with LV relaxation [38,39]. A significant difference in $\mathrm{SrR}_{\mathrm{E}}$ was observed in posterior segments at the $\mathrm{Ct}$ level in carrier and affected dogs. $\mathrm{SrR}_{\mathrm{E}}$ tended to decrease in other LV segments. The results of segmental STE analysis suggest an impairment of LV relaxation in the basal inferoposterior segments of $\mathrm{CXMD}_{\mathrm{J}}$ - affected dogs prior to a detectable decrease in global indices of cardiac function. In previous studies, pathological lesions were frequently observed in the posterior and lateral wall of the left ventricle in patients and dogs with DMD $[9,40,41]$. Previous reports have indicated that TDI-derived parameters also identified myocardial dysfunction in the LV free wall [11,14-17,42], which supported our results.

Circumferential strain parameters in affected dogs were not significantly changed in the present study. In contrast, Mertens et al. reported significant decreases in TDI-derived strain indices in the apical, mid and basal level of LV long-axis views in DMD patients [15]. One possible explanation for this difference is more advanced disease in the previously reported population, supported by the presence of obvious LV dilation in the patients of that study. A second possibility is different measurement techniques. Mizuguchi et al. have suggested that LV systolic dysfunction may begin with reduced longitudinal shortening that is compensated by augmented circumferential shortening in early stages. Therefore, one could hypothesize that STE performed using long-axis views is a more sensitive method than with short-axis views, although it was not evaluated in the present study.

E wave velocity in carrier dogs was significantly increased compared with normal dogs. Increased $\mathrm{E}$ wave was noticed in dogs with overt and occult dilated cardiomyopathy (DCM), which may suggest diastolic dysfunction [43]. However, in the present study, the other measured parameters derived from transmitral flow, such as DcT and A wave velocity, were all within the reference range and no statistical significance was found among groups. In addition, the TMF pattern was not the typical restrictive pattern (i.e. $\mathrm{E} / \mathrm{A}>2$ as well as short DcT) in any individual carrier dogs $[43,44]$. The clinical relevance of this finding is uncertain given the relatively small magnitude of difference and the large amount of overlap in values among groups. In addition, higher value of $\mathrm{E} / \mathrm{SrR}_{\mathrm{E}}$ in carrier dogs might be influenced by the increased $\mathrm{E}$ wave. E' measured using TDI was significantly reduced in affected dogs compared with normal dogs. This is similar to a previous report of reduced peak E' velocity in patients with DMD [13].

Duchenne's cardiomyopathy in a carrier female was previously reported, though it was found to be mild compared with that in an affected male [45,46]. In the present study, there was significant difference in segmental assessment of $\mathrm{SrR}_{\mathrm{E}}$ between normal and carrier female dogs as well as affected dogs. Since our carrier females

Table 2 Effects of sedation on echocardiographic parameters

\begin{tabular}{lllccc}
\hline Index & & Unit & Awake & Sedated & $P$ value \\
\hline Conventional echocardiography & HR & $\mathrm{bpm}$ & $89.10 \pm 27.29$ & $69.61 \pm 7.01$ & $<0.05$ \\
& ESVI & $\mathrm{mL} / \mathrm{m}^{2}$ & $27.37 \pm 3.64$ & $21.43 \pm 3.61$ & 0.0042 \\
\hline Transmitral flow & A wave & $\mathrm{cm} / \mathrm{sec}$ & $46.33 \pm 12.41$ & $34.22 \pm 8.28$ & 0.015 \\
\hline
\end{tabular}

ESVI = Left ventricular end-systolic index; $\mathrm{A}=$ Peak velocity of late diastolic flow in transmitral flow (results with $P$ value $<0.05$ ). 
Table 3 Conventional echocardiographic parameters of each group

\begin{tabular}{lcccc}
\hline Index & Unit & Normal dogs & Carrier dogs & Affected dogs \\
\hline $\mathrm{HR}$ & $\mathrm{bpm}$ & $92.54 \pm 11.22$ & $106.39 \pm 26.22$ & $102.16 \pm 35.79$ \\
$\mathrm{EF}$ & $\%$ & $65.42 \pm 8.13$ & $67.13 \pm 10.35$ & $62.89 \pm 13.05$ \\
$\mathrm{FS}$ & $\%$ & $35.04 \pm 6.66$ & $36.92 \pm 8.41$ & $33.61 \pm 9.87$ \\
\hline $\mathrm{EDVI}$ & $\mathrm{mL} / \mathrm{m}^{2}$ & $59.19 \pm 19.53$ & $69.79 \pm 20.62$ & $53.35 \pm 27.03$ \\
ESVI & $\mathrm{mL} / \mathrm{m}^{2}$ & $15.43 \pm 4.57$ & $20.04 \pm 11.02$ & $17.87 \pm 13.75$ \\
\hline LA/Ao & & $1.22 \pm 0.095$ & $1.17 \pm 0.14$ & $1.08 \pm 0.081$ \\
\hline
\end{tabular}

$\mathrm{EF}=$ Ejection fraction; FS = Fractional shortening; EVDI = Left ventricular end-diastolic index; ESVI = Left ventricular end-systolic index; LA/Ao = Left atrial diameter/aortic root diameter ratio.

Table 4 Echocardiographic systolic and diastolic parameters using Doppler of each group

\begin{tabular}{llcccc}
\hline Index & & Unit & Normal dogs & Carrier dogs & Affected dogs \\
\hline Systolic time intervals & PEP/ET & & $0.21 \pm 0.037$ & $0.21 \pm 0.046$ & $0.22 \pm 0.085$ \\
\hline Transmitral flow & E wave & $\mathrm{cm} / \mathrm{sec}$ & $74.71 \pm 13.42$ & $87.42 \pm 10.89 \dagger$ & $66.44 \pm 10.19$ \\
& A wave & $\mathrm{cm} / \mathrm{sec}$ & $45.79 \pm 14.68$ & $45.71 \pm 8.09$ & $44.61 \pm 8.98$ \\
& E/A & & $1.82 \pm 0.71$ & $1.98 \pm 0.44$ & $1.58 \pm 0.52$ \\
& DcT & $\mathrm{msec}$ & $92.29 \pm 8.20$ & $91.54 \pm 14.44$ & $91.06 \pm 14.73$ \\
\hline Isovolumic relaxation time & & $\mathrm{msec}$ & $32.13 \pm 11.49$ & $28.21 \pm 10.07$ & $39.28 \pm 13.61$ \\
\hline Mitral annular velocity & $\mathrm{S}^{\prime}$ wave & $\mathrm{cm} / \mathrm{sec}$ & $10.67 \pm 1.60$ & $12.17 \pm 5.94$ & $7.39 \pm 1.25$ \\
& $\mathrm{E}^{\prime}$ wave & $\mathrm{cm} / \mathrm{sec}$ & $12.13 \pm 2.62$ & $11.33 \pm 2.12$ & $8.67 \pm 1.65+$ \\
& E/E' & & $6.39 \pm 1.57$ & $7.89 \pm 1.41$ & $8.48 \pm 2.17$ \\
\hline
\end{tabular}

t: Significant difference compared with normal dogs by multiple comparison $(P<0.05)$.

$\mathrm{PEP}=$ Pre-ejection period; $\mathrm{ET}=$ Left ventricular ejection time; $\mathrm{E}=$ Peak velocity of early diastolic flow in transmitral flow; $\mathrm{A}=$ Peak velocity of late diastolic flow in transmitral flow; $\mathrm{DCT}=$ Deceleration time of early diastolic flow; $\mathrm{S}^{\prime}=$ Peak mitral annular velocity during systole; $\mathrm{E}^{\prime}=$ Peak mitral annular velocity during early diastole.

Table 5 STE indices of each group

\begin{tabular}{|c|c|c|c|c|c|}
\hline Index & & Unit & Normal dogs & Carrier dogs & Affected dogs \\
\hline \multirow[t]{4}{*}{ Radial } & $S R$ & $\%$ & $44.50 \pm 9.63$ & $49.58 \pm 14.76$ & $46.68 \pm 12.63$ \\
\hline & $\mathrm{SrR}_{S}$ & /sec & $2.71 \pm 0.41$ & $2.82 \pm 0.68$ & $2.78 \pm 0.63$ \\
\hline & $\mathrm{SrR}_{\mathrm{E}}$ & /sec & $-3.06 \pm 0.50$ & $-2.55 \pm 0.73$ & $-2.23 \pm 0.95$ \\
\hline & $\mathrm{E} / \mathrm{SrR} \mathrm{E}_{\mathrm{E}}$ & & $-24.81 \pm 5.21$ & $-36.20 \pm 8.73 \dagger$ & $-34.24 \pm 12.88$ \\
\hline \multirow[t]{4}{*}{ Circumferential } & SC & $\%$ & $-20.87 \pm 3.86$ & $-22.76 \pm 5.14$ & $-23.04 \pm 5.38$ \\
\hline & $\mathrm{SrC}_{\mathrm{S}}$ & /sec & $-2.49 \pm 0.26$ & $-2.77 \pm 0.72$ & $-3.04 \pm 0.86$ \\
\hline & $\mathrm{SrC}_{\mathrm{E}}$ & /sec & $2.84 \pm 0.61$ & $2.92 \pm 0.78$ & $2.70 \pm 0.49$ \\
\hline & $\mathrm{E} / \mathrm{Sr} \mathrm{C}_{\mathrm{E}}$ & & $27.15 \pm 7.08$ & $31.80 \pm 8.92$ & $25.50 \pm 6.48$ \\
\hline
\end{tabular}

†: Significant difference compared with normal dogs by multiple comparison $(P<0.05)$.

$\mathrm{SR}=$ peak systolic radial strain; $\mathrm{SrR}_{\mathrm{S}}=$ Peak radial strain rate during systole; $\mathrm{SrR}_{\mathrm{E}}=$ Peak radial strain rate during early diastole; $\mathrm{SC}=\mathrm{Peak}$ systolic circumferential strain; $\mathrm{SrC}_{\mathrm{S}}=$ Peak circumferential strain rate during systole; $\mathrm{SrC}_{\mathrm{E}}=$ Peak circumferential strain rate during early diastole.

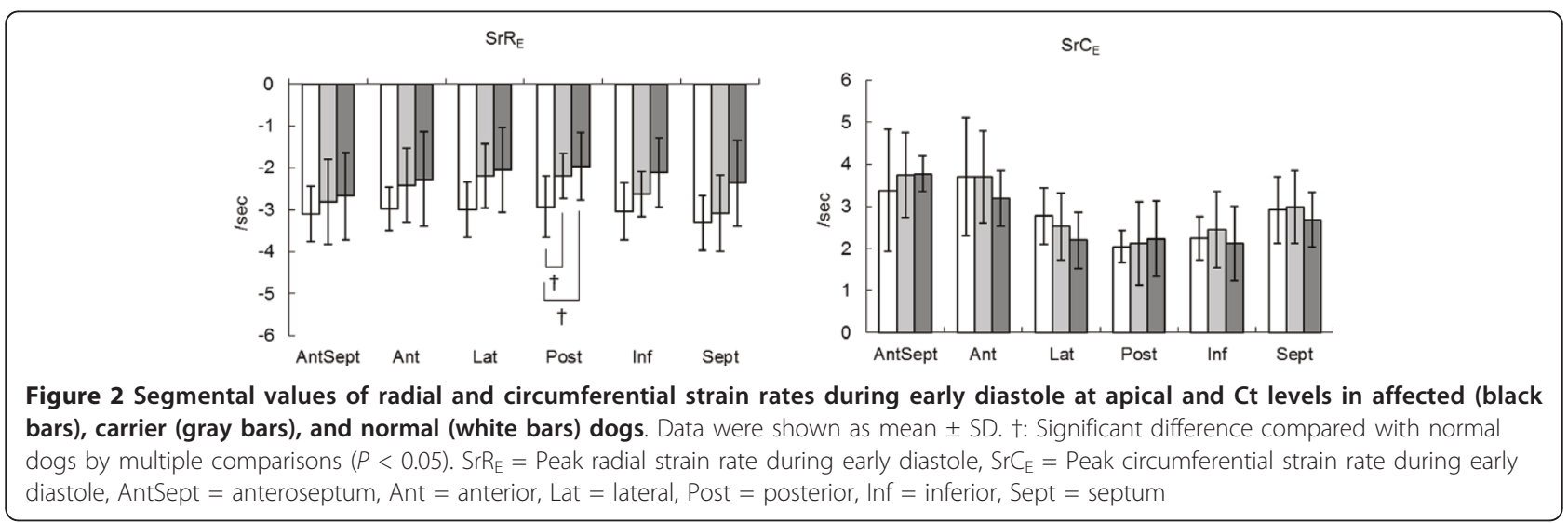


Table 6 Segmental values of peak radial strain rate during early diastole at Ct level in each group

\begin{tabular}{ccccc}
\hline Segment & Unit & Normal dogs & Carrier dogs & Affected dogs \\
\hline Anterioseptum & $/ \mathrm{sec}$ & $-3.10 \pm 0.66$ & $-2.81 \pm 1.01$ & $-2.68 \pm 1.05$ \\
Anterior & $/ \mathrm{sec}$ & $-2.98 \pm 0.51$ & $-2.43 \pm 0.89$ & $-2.27 \pm 1.13$ \\
Lateral & $/ \mathrm{sec}$ & $-3.00 \pm 0.66$ & $-2.19 \pm 0.76$ & $-2.04 \pm 1.01$ \\
Posterior & $/ \mathrm{sec}$ & $-2.93 \pm 0.73$ & $-2.19 \pm 0.54 \dagger$ & $-1.96 \pm 0.81 \dagger$ \\
Inferior & $/ \mathrm{sec}$ & $-3.04 \pm 0.68$ & $-2.63 \pm 0.53$ & $-2.10 \pm 0.83$ \\
Septum & $/ \mathrm{sec}$ & $-3.32 \pm 0.64$ & $-3.08 \pm 0.91$ & $-2.36 \pm 1.03$ \\
\hline
\end{tabular}

†: Significant difference compared with normal dogs by multiple comparison $(P<0.05)$.

were young to middle-aged, it is possible that follow-up evaluation would reveal myocardial impairment.

In the present study, low dose of acepromazine was used for sedation. The influence of sedation was seen in EDVI, and A wave velocity of TMF. Schaefer et al. demonstrated increased A waves of TMF and myocardial velocity using TDI under anesthesia in normal mice, while increased heart rates were observed at the same time [47]. They speculated that changes in heart rates constituted one of the factors causing increased A wave velocity. Since changes in A waves in our study were accompanied by decreased heart rates, there might have been a relationship. Although further study is needed, parameters influenced by sedation appeared to be less important in the overall interpretation of our results. Additionally, proportions of sedated dogs in each group were similar.

There were several limitations in the present study. First, the number of dogs available for each group was limited and age distribution was relatively wide in all groups because of the difficulty in maintaining a sufficient number of $\mathrm{CXMD}_{\mathrm{J}} \mathrm{s}$. Second, body weight in affected dogs was significantly lower than in normal dogs. However, we consider that this difference would be less likely to affect our results. Third, one carrier dog had mild MR. A report described mitral valve prolapse in DMD patients, and MR was considered to be responsible for LV dilation [48]. In the present study, because LV dilation was not observed in that carrier dog, MR was more likely caused by myxomatous degeneration of the mitral valve, the most common acquired heart disease in dogs. In this case, MR was considered to be too mild to likely affect our results. Fourth, the accuracy of strain measurement depends on the quality of 2-dimensional echocardiography and frame rate. The mean frame rates per cardiac cycle in normal, carrier and affected dogs were 57.4, 49.4 and 45.1, respectively. The frame rate per cardiac cycle was relatively low due to the relatively higher heart rate compared with humans (about 70-110 frames when the human heart rate was considered to be $60 \mathrm{bpm}$ [49]). This may affect the accuracy of tracking quality, especially in early diastolic parameters. Further investigation using newer methods might detect change more precisely [50]. Finally, given the characteristics of this disease, differences in the sex ratio among the groups were unavoidable. Since significant differences between males and females in some STE parameters have been reported in a human study [51], the results could have been influenced by gender. Since the number of normal dogs was small when categorized by gender, further studies using a greater number of dogs are warranted. In addition, there should be some differences in expression of the disease among the affected dogs, and CXMDJ might have less severe disease compared to the human patients.

\section{Conclusions}

The myocardial strain rate by STE served to detect the impaired cardiac diastolic function in $\mathrm{CXMD}_{\text {J }}$ without any obvious LV dilation or clinical signs. The radial strain rate may be a useful parameter to detect early myocardial impairment in $\mathrm{CXMD}_{\mathrm{J}}$.

\section{List of abbreviations}

LV: left ventricular; STE: speckle tracking echocardiography; CXMDJ: canine Xlinked muscular dystrophy; TDI: tissue Doppler imaging; DMD: Duchenne's muscular dystrophy; Ct: chordae tendineae; LVIDd: left ventricular enddiastolic internal diameter; LVIDs: left ventricular end-systolic internal diameter; FS: fractional shortening; EF: ejection fraction; EDVI: end-diastolic volume index; ESVI: end-systolic volume index; EDV: end-diastolic volume; ESV: end-systolic volume; BSA: body surface area; LAD: left atrial diameter; AoD: aortic root diameter; LA/Ao: left atrium to aorta ratio; PEP: pre-ejection period; ET: ejection time; TMF: transmitral flow; DcT: deceleration time; IVRT: isovolumic relaxation time; MAV: mitral annulus velocity; SR: peak systolic radial strain; SC: peak systolic circumferential strain; SrRs: peak radial strain rate during systole; $\mathrm{SrR}_{\mathrm{E}}$ : peak radial strain rate during early diastole; $\mathrm{SrC}_{\mathrm{S}}$ : peak circumferential strain rate during systole; $\mathrm{SrC}_{\mathrm{E}}$ : peak circumferential strain rate during early diastole; MR: mitral regurgitation

\section{Acknowledgements and funding}

Supported by Health Sciences Research Grants for Research on Psychiatric and Neurological Diseases and Mental Health (H12-kokoro-025, H15-kokoro021. H18-kokoro-019), Human Genome and Gene Therapy (H13-genome-001, H16-genome-003) from the Ministry of Health, Labor and Welfare of Japan, Health and Labor Sciences Research Grants for Translation Research and (H19-translational research-003) from the Ministry of Health, Labor and Welfare of Japan, Grants-in-Aid for Scientific Research from the Ministry of Education, Science, Sports and Culture of Japan (to S.T. and A.N.).

\section{Author details}

${ }^{1}$ Department of Surgery 1, School of Veterinary Medicine, Azabu University, Kanagawa, Japan. ${ }^{2}$ Department of Molecular Therapy, National Institute of Neuroscience, National Center of Neurology and Psychiatry, Tokyo, Japan.

\section{Authors' contributions}

HT performed echocardiographic examinations for all dogs and statistical analysis. NY and ST contributed to hold this genetic colony of CXMDJ, and 
carried out genetic examinations to determine each dog's genetic status. YF and YW conceived of the study, and participated in its design and coordination. All authors read and approved the final manuscript.

\section{Competing interests}

The authors declare that they have no competing interests.

Received: 30 September 2010 Accepted: 25 May 2011

Published: 25 May 2011

\section{References}

1. Cullen MJ, Mastaglia FL: Morphological changes in dystrophic muscle. $\mathrm{Br}$ Med Bull 1980, 36(2):145-122.

2. Nigro G, Comi LI, Politano L, Bain RJ: The incidence and evolution of cardiomyopathy in Duchenne muscular dystrophy. Int J Cardiol 1990, 26(3):271-277

3. Perloff JK, de Leon AC, O'Doherty D: The cardiomyopathy of progressive muscular dystrophy. Circulation 1966, 33(4):625-648.

4. Danilowicz D, Rutkowski M, Myung D, Schively D: Echocardiography in duchenne muscular dystrophy. Muscle Nerve 1980, 3(4):298-303.

5. Farah MG, Evans EB, Vignos PJ Jr: Echocardiographic evaluation of left ventricular function in Duchenne's muscular dystrophy. Am J Med 1980, 69(2):248-254.

6. Hunsaker RH, Fulkerson PK, Barry FJ, Lewis RP, Leier CV, Unverferth DV Cardiac function in Duchenne's muscular dystrophy. Results of 10-year follow-up study and noninvasive tests. Am J Med 1982, 73(2):235-238.

7. D'Orsogna L, O'Shea JP, Miller G: Cardiomyopathy of Duchenne muscular dystrophy. Pediatr Cardiol 1988, 9(4):205-213.

8. Sasaki K, Sakata K, Kachi E, Hirata S, Ishihara T, Ishikawa K: Sequential changes in cardiac structure and function in patients with Duchenne type muscular dystrophy: a two-dimensional echocardiographic study. Am Heart J 1998, 135(6 Pt 1):937-944

9. Yugeta N, Urasawa N, Fujii Y, Yoshimura M, Yuasa K, Wada MR, Nakura M, Shimatsu Y, Tomohiro M, Takahashi A, Machida N, Wakao Y, Nakamura A, Takeda S: Cardiac involvement in Beagle-based canine X-linked muscular dystrophy in Japan (CXMDJ): electrocardiographic, echocardiographic, and morphologic studies. BMC CardiovasC Disord 2006, 6:47.

10. $\mathrm{Yu}$ CM, Sanderson JE, Marwick TH, Oh JK: Tissue Doppler imaging a new prognosticator for cardiovascular diseases. J Am Coll Cardiol 2007, 49(19):1903-1914.

11. Mori K, Edagawa T, Inoue M, Nii M, Nakagawa R, Takehara $Y$, Kuroda $Y$, Tatara K: Peak negative myocardial velocity gradient and wall-thickening velocity during early diastole are noninvasive parameters of left ventricular diastolic function in patients with Duchenne's progressive muscular dystrophy. J Am Soc Echocardiogr 2004, 17(4):322-329.

12. Bahler RC, Mohyuddin T, Finkelhor RS, Jacobs IB: Contribution of Doppler tissue imaging and myocardial performance index to assessment of left ventricular function in patients with Duchenne's muscular dystrophy. $J$ Am Soc Echocardiogr 2005, 18(6):666-673.

13. Mori K, Hayabuchi $Y$, Inoue M, Suzuki M, Sakata M, Nakagawa R, Kagami S, Tatara K, Hirayama $Y$, Abe $Y$ : Myocardial strain imaging for early detection of cardiac involvement in patients with Duchenne's progressive muscular dystrophy. Echocardiography 2007, 24(6):598-608.

14. Ogata H, Nakatani S, Ishikawa Y, Negishi A, Kobayashi M, Minami R: Myocardial strain changes in Duchenne muscular dystrophy without overt cardiomyopathy. Int J Cardiol 2007, 115(2):190-195.

15. Mertens L, Ganame J, Claus P, Goemans N, Thijs D, Eyskens B, Van Laere D, Bijnens B, D'Hooge J, Sutherland GR, Buyse G: Early regional myocardia dysfunction in young patients with Duchenne muscular dystrophy. J Am Soc Echocardiogr 2008, 21(9):1049-1054.

16. Chetboul V, Carlos C, Blot S, Thibaud JL, Escriou C, Tissier R, Retortillo JL, Pouchelon JL: Tissue Doppler assessment of diastolic and systolic alterations of radial and longitudinal left ventricular motions in Golden Retrievers during the preclinical phase of cardiomyopathy associated with muscular dystrophy. Am J Vet Res 2004, 65(10):1335-1341.

17. Chetboul V, Escriou C, Tessier D, Richard V, Pouchelon JL, Thibault H, Lallemand F, Thuillez C, Blot S, Derumeaux G: Tissue Doppler imaging detects early asymptomatic myocardial abnormalities in a dog model of Duchenne's cardiomyopathy. Eur Heart J 2004, 25(21):1934-1939.
18. Guillaume MD, Phoon CK, Chun AJ, Srichai MB: Delayed enhancement cardiac magnetic resonance imaging in a patient with Duchenne muscular dystrophy. Tex Heart Inst J 2008, 35(3):367-368

19. Silva MC, Meira ZM, Gurgel Giannetti J, da Silva MM, Campos AF, Barbosa Mde M, Starling Filho GM, Ferreira Rde A, Zatz M, Rochitte CE: Myocardial delayed enhancement by magnetic resonance imaging in patients with muscular dystrophy. J Am Coll Cardiol 2007, 49(18):1874-1879.

20. Nishimura T, Yanagisawa A, Sakata H, Sakata K, Shimoyama K, Ishihara T, Yoshino H, Ishikawa K: Thallium-201 single photon emission computed tomography (SPECT) in patients with duchenne's progressive muscular dystrophy: a histopathologic correlation study. Jpn Circ J 2001, 65(2):99-105.

21. Amundsen $B H$, Helle-Valle $T$, Edvardsen $T$, Torp $H$, Crosby J, Lyseggen $E$, Stoylen A, Ihlen H, Lima JA, Smiseth OA, Slordahl SA: Noninvasive myocardial strain measurement by speckle tracking echocardiography: validation against sonomicrometry and tagged magnetic resonance imaging. J Am Coll Cardiol 2006, 47(4):789-793.

22. Becker M, Bilke E, Kuhl H, Katoh M, Kramann R, Franke A, Bucker A, Hanrath P, Hoffmann R: Analysis of myocardial deformation based on pixel tracking in two dimensional echocardiographic images enables quantitative assessment of regional left ventricular function. Heart 2006, 92(8):1102-1108

23. Friedberg MK, Slorach C: Relation between left ventricular regional radial function and radial wall motion abnormalities using two-dimensional speckle tracking in children with idiopathic dilated cardiomyopathy. Am J Cardiol 2008, 102(3):335-339.

24. Meluzin J, Spinarova L, Hude P, Krejci J, Poloczkova H, Podrouzkova H, Pesl M, Orban M, Dusek L, Korinek J: Left ventricular mechanics in idiopathic dilated cardiomyopathy: systolic-diastolic coupling and torsion. J Am Soc Echocardiogr 2009, 22(5):486-493.

25. Meluzin J, Spinarova L, Hude P, Krejci J, Podrouzkova H, Pesl M, Orban M, Dusek L, Jarkovsky J, Korinek J: Estimation of left ventricular filling pressures by speckle tracking echocardiography in patients with idiopathic dilated cardiomyopathy. Eur J Echocardiogr

26. Shimatsu Y, Yoshimura M, Yuasa K, Urasawa N, Tomohiro M, Nakura M, Tanigawa M, Nakamura A, Takeda S: Major clinical and histopathological characteristics of canine X-linked muscular dystrophy in Japan, CXMDJ. Acta Myol 2005, 24(2):145-154.

27. Shimatsu $Y$, Katagiri K, Furuta T, Nakura M, Tanioka $Y$, Yuasa $K$, Tomohiro M, Kornegay JN, Nonaka I, Takeda S: Canine X-linked muscular dystrophy in Japan (CXMDJ). Exp Anim 2003, 52(2):93-97.

28. Urasawa N, Wada MR, Machida N, Yuasa K, Shimatsu Y, Wakao Y, Yuasa S, Sano T, Nonaka I, Nakamura A, Takeda S: Selective vacuolar degeneration in dystrophin-deficient canine Purkinje fibers despite preservation of dystrophin-associated proteins with overexpression of Dp71. Circulation 2008, 117(19):2437-2448

29. Jacobs G, Mahjoob K: Multiple regression analysis, using body size and cardiac cycle length, in predicting echocardiographic variables in dogs. Am J Vet Res 1988, 49(8):1290-1294.

30. Rishniw M, Erb HN: Evaluation of four 2-dimensional echocardiographic methods of assessing left atrial size in dogs. J Vet Intern Med 2000, 14(4):429-435.

31. Atkins CE, Snyder PS: Systolic time intervals and their derivatives for evaluation of cardiac function. J Vet Intern Med 1992, 6(2):55-63.

32. Chetboul V, Sampedrano CC, Concordet D, Tissier R, Lamour T, Ginesta J, Gouni V, Nicolle AP, Pouchelon JL, Lefebvre HP: Use of quantitative twodimensional color tissue Doppler imaging for assessment of left ventricular radial and longitudinal myocardial velocities in dogs. Am J Vet Res 2005, 66(6):953-961.

33. Oyama MA, Sisson DD, Bulmer BJ, Constable PD: Echocardiographic estimation of mean left atrial pressure in a canine model of acute mitral valve insufficiency. J Vet Intern Med 2004, 18(5):667-672.

34. Kim HK Sohn DW, Lee SE, Choi SY, Park JS, Kim YJ, Oh BH, Park YB, Choi YS: Assessment of left ventricular rotation and torsion with two-dimensional speckle tracking echocardiography. J Am Soc Echocardiogr 2007, 20(1):45-53.

35. Chetboul V, Serres F, Gouni V, Tissier R, Pouchelon JL: Noninvasive assessment of systolic left ventricular torsion by 2-dimensional speckle tracking imaging in the awake dog: repeatability, reproducibility, and comparison with tissue Doppler imaging variables. J Vet Intern Med 2008, 22(2):342-350. 
36. Suffoletto MS, Dohi K, Cannesson M, Saba S, Gorcsan J III: Novel speckletracking radial strain from routine black-and-white echocardiographic images to quantify dyssynchrony and predict response to cardiac resynchronization therapy. Circulation 2006, 113(7):960-968.

37. Takano H, Fujii Y, Ishikawa R, Aoki T, Wakao Y: Comparison of left ventricular contraction profiles among small, medium, and large dogs by use of two-dimensional speckle-tracking echocardiography. Am J Vet Res 71(4):421-427.

38. Park TH, Nagueh SF, Khoury DS, Kopelen HA, Akrivakis S, Nasser K, Ren G, Frangogiannis NG: Impact of myocardial structure and function postinfarction on diastolic strain measurements: implications for assessment of myocardial viability. Am J Physiol Heart Circ Physiol 2006, 290(2):H724-731

39. Wang J, Khoury DS, Thohan V, Torre-Amione G, Nagueh SF: Global diastolic strain rate for the assessment of left ventricular relaxation and filling pressures. Circulation 2007, 115(11):1376-1383.

40. Moriuchi T, Kagawa N, Mukoyama M, Hizawa K: Autopsy analyses of the muscular dystrophies. Tokushima J Exp Med 1993, 40(1-2):83-93.

41. Frankel KA, Rosser RJ: The pathology of the heart in progressive muscular dystrophy: epimyocardial fibrosis. Hum Pathol 1976, 7(4):375-386.

42. Mori K, Manabe T, Nii M, Hayabuchi Y, Kuroda Y, Tatara K: Myocardial integrated ultrasound backscatter in patients with Duchenne's progressive muscular dystrophy. Heart 2001, 86(3):341-342.

43. O'Sullivan ML, O'Grady MR, Minors SL: Assessment of diastolic function by Doppler echocardiography in normal Doberman Pinschers and Doberman Pinschers with dilated cardiomyopathy. J Vet Intern Med 2007, 21(1):81-91.

44. Nagueh SF, Appleton CP, Gillebert TC, Marino PN, Oh JK, Smiseth OA, Waggoner AD, Flachskampf FA, Pellikka PA, Evangelisa A:

Recommendations for the evaluation of left ventricular diastolic function by echocardiography. Eur J Echocardiogr 2009, 10(2):165-193.

45. Ueda Y, Kawai H, Adachi K, Naruo T, Saito S: Cardiac dysfunction in female gene carriers of Duchenne muscular dystrophy. Rinsho Shinkeigaku 1995, 35(11):1191-1198.

46. Mirabella M, Servidei S, Manfredi G, Ricci E, Frustaci A, Bertini E, Rana M, Tonali P: Cardiomyopathy may be the only clinical manifestation in female carriers of Duchenne muscular dystrophy. Neurology 1993, 43(11):2342-2345.

47. Schaefer A, Meyer GP, Brand B, Hilfiker-Kleiner D, Drexler H, Klein G: Effects of anesthesia on diastolic function in mice assessed by echocardiography. Echocardiography 2005, 22(8):665-670

48. Sanyal SK, Johnson WW, Dische MR, Pitner SE, Beard C: Dystrophic degeneration of papillary muscle and ventricular myocardium. A basis for mitral valve prolapse in Duchenne's muscular dystrophy. Circulation 1980, 62(2):430-438

49. Helle-Valle T, Crosby J, Edvardsen T, Lyseggen E, Amundsen BH, Smith HJ, Rosen BD, Lima JA, Torp H, Ihlen H, Smiseth OA: New noninvasive method for assessment of left ventricular rotation: speckle tracking echocardiography. Circulation 2005, 112(20):3149-3156.

50. Tournoux F, Chan RC, Handschumacher MD, Salgo IS, Manzke R, Settlemier S, Guerrero JL, Cury RC, Weyman AE, Picard MH: Estimation of radial strain and rotation using a new algorithm based on speckle tracking. J Am Soc Echocardiogr 2008, 21(10):1168-1174.

51. Hurlburt HM, Aurigemma GP, Hill JC, Narayanan A, Gaasch WH, Vinch CS, Meyer TE, Tighe DA: Direct ultrasound measurement of longitudinal, circumferential, and radial strain using 2-dimensional strain imaging in normal adults. Echocardiography 2007, 24(7):723-731.

\section{Pre-publication history}

The pre-publication history for this paper can be accessed here: http://www.biomedcentral.com/1471-2261/11/23/prepub

doi:10.1186/1471-2261-11-23

Cite this article as: Takano et al:: Assessment of left ventricular regional function in affected and carrier dogs with duchenne muscular dystrophy using speckle tracking echocardiography. BMC Cardiovascular Disorders 2011 11:23.

\section{Submit your next manuscript to BioMed Central and take full advantage of:}

- Convenient online submission

- Thorough peer review

- No space constraints or color figure charges

- Immediate publication on acceptance

- Inclusion in PubMed, CAS, Scopus and Google Scholar

- Research which is freely available for redistribution

Submit your manuscript at www.biomedcentral.com/submit
Biomed Central 